\title{
Students' Perceptions and Usage of Short Anatomy Videos: A Preliminary Study
}

\author{
Percepciones de los Estudiantes y el Uso de Videos Cortos de Anatomía: Un Estudio Preliminar
}

Goran Strkalj'; Anneliese Hulme1; Joyce El-Haddad'; Kehui Luo ${ }^{2}$; Dirk Crafford ${ }^{1}$ \& Michael Rampe

STRKALJ, G.; HULME, A.; EL-HADDAD, J.; LUO, K.; CRAFFORD, D. \& RAMPE, M. Students' perceptions and usage of short anatomy videos: A preliminary study. Int. J. Morphol., 36(2):493-499, 2018.

SUMMARY: The efficacy of videos in anatomy education is still being debated. It appears that one of the major factors discouraging learners to use videos has been their length. To counteract this, 24 short videos (the longest lasting 1 minute and 13 seconds), were created for a course on musculoskeletal anatomy. Videos focused on identification of muscles of the limbs and their relations by area. The aim of this preliminary study was to assess students' perception of value of the videos and their utilisation. The number of views for each video was recorded. A questionnaire based survey was carried out focusing on students' perception of the educational usefulness of the videos. On average, each video had 339.5 views. Out of 312 students enrolled in the course, 210 completed the survey (67.3\% response rate). A total of 181 respondents $(86.2 \%)$ watched the videos and a majority perceived them useful in: Learning about the anatomy of the limbs $(68 \%)$, preparation for the laboratory $(56.9 \%)$, post-laboratory revision $(65.6 \%)$ and preparation for the practical test $(66.3 \%)$. Asked for feedback, students requested an increase in the number of videos to include structures other than muscles. Students reported to perceive videos as a useful resource in their musculoskeletal anatomy course. The shortness of the videos made them easy to access and use repeatedly. Future, more in-depth studies, based on the utilisation of the existing and newly produced videos, might throw more light on their full educational potential.

KEY WORDS: Anatomical sciences education; Musculoskeletal anatomy; Videos; Human gross anatomy.

\section{INTRODUCTION}

One of the main features of modern anatomy education has been the application of new technologies for learning and teaching (McNulty et al., 2009; Topping, 2014; Collins et al., 2015; Lochner et al., 2016; Trelease, 2016). Technology based approaches have been utilised for several reasons including the enrichment of the learning experience, to substitute some of the traditional teaching methods such as dissection and to compensate for decreasing face to face teaching hours dedicated to anatomy (Granger \& Calleson, 2007; Topping; Collins et al.). One of the oldest, but still evolving, resources based on technological advancement have been videos. The "motion pictures", since their invention more than a century ago, offered themselves for educational purposes. In medical and science education (including anatomy), they became more widely used from the 1970s with the appearance of the Video Home Service (VHS) technology (Ogunranti,
1987). This enabled easy access to video recordings at a relatively low cost (Trelease). In the following decades, technological improvements continued to increase the accessibility and quality of audio-visual recordings, while at the same time decreasing the cost needs for production and viewing. The formats in which videos have been presented evolved from VHS, via Compact Disc ReadOnly Memory (CD-ROM) and Digital Versatile/Video Disc (DVD) to specialised Web sites and services such as YouTube (Bacro et al., 2009; Jaffar, 2012; Barry et al., 2016; Trelease; Hulme \& Strkalj, 2017).

However, the efficacy of videos in anatomy education is still being debated. Some studies investigating students' utilization of videos suggested that this had resulted in better grades, while other research showed no significant change or even reduced scores in the anatomy

\footnotetext{
${ }^{1}$ Department of Chiropractic, Faculty of Science and Engineering, Macquarie University, Sydney, Australia.

${ }^{2}$ Department of Statistics, Faculty of Science and Engineering, Macquarie University, Sydney, Australia.

${ }^{3}$ Learning Innovation Hub, Macquarie University, Sydney, Australia.
} 
exams (Saxena et al., 2008; Mahmud et al., 2011; Topping; Collins et al.; Choi-Lundberg et al., 2016; Hulme \& Strkalj). Similarly, there has been a variety of findings related to student usage and satisfaction (Topping; O'Brien et al., 2015; Lochner et al.; Hulme \& Strkalj).On the other hand, students seem to favour videos, especially those found on the World Wide Web (Jaffar). A recent study from Ireland for example, found that "the vast majority of students had employed webbased platforms to source information with $78 \%$ using YouTube as their primary source of anatomy-related video clips" (Barry et al.).

Thus, it might be suggested that not videos as such, but their format, content and availability are key factors influencing students' not to use them. While reasons for utilisation of videos are many, it could be argued that one of the factors discouraging learners from using videos has been their length. The latest generations of learners, the Millennials and now the post-Millennials, who were branded Digital Natives, seem to prefer shorter, faster forms of video presentation, starting with graphical representations (Prensky, 2001a,b; Tapscott, 2008). As exposure to digital material becomes commonplace and the norm for current and future generations, it seems pertinent to qualify the key factors that contribute to student usage to maximise the value of this resource.

To counteract this possible saturation with longer forms, a series of short videos were created at Macquarie University and made available to students enrolled in an anatomy course on musculoskeletal anatomy. The aim of this preliminary study, carried out in the 2015 academic year, was to make a preliminary assessment of students' perception of value of these short videos and the frequency and extent to which they were utilised.

\section{MATERIAL AND METHOD}

Population. The research was carried out among students taking a course in musculoskeletal anatomy covering the regional anatomy of the Limbs and Back (LB) at Macquarie University, Sydney. Although these students were enrolled into different programs, most of them were undertaking studies in Chiropractic, Medical Science, Human Movement and Human Biology. The musculoskeletal anatomy course is one semester long with three hours of lectures, two hours of laboratory based practical work and one hour classroom tutorial per week. In this course students do not dissect in their practical classes, but study anatomy through the inspection of prosected specimens.
Twenty-four video clips were created to help students prepare for the laboratory classes, revise anatomy after classes, prepare for the test, provide an opportunity to learn from the specimens while not in the laboratory and to generally increase students' exposure to the specimens. Cadaveric specimens utilised in the video production were the ones used in the laboratory sessions in the course. All bodies were acquired through the voluntary body donation.

In this study, the videos were limited in scope by focusing only on the demonstration of the upper and lower limb muscles and their relations. The organisation of the videos was mainly by compartments and adjusted to the course's learning outcomes. The videos made were purposely short ranging in length from 14 seconds to 1 minute and 13 seconds.

The production of the videos was relatively simple and carried out by two senior students under the supervision of an academic staff member. They were made using a Canon EOS 1100D digital camera. No editing was carried out afterwards. In these videos, only specimens were shown while the presenter pointed to relevant anatomical structures with verbal description and explanation. Several versions were made to avoid technical and content mistakes. Recorded videos were reviewed and the best versions were posted on iLearn (a Moodle based platform). All posted videos were accessible throughout the semester and there were no access restrictions to the students enrolled into the course.

Instrument. Total number of views for each video was recorded through iLearn. In addition, a questionnaire based survey was carried out that recorded basic demographic data and information on a series of questions focusing on students' utilisation and perception of the videos. The respondents were asked if and approximately how many times they watched the videos and if they did not, what were the reasons for not watching them. If they watched the videos, they were also asked for feedback on the content and format of the videos. Furthermore, the questionnaire included five perception related items in five-point Likert scale (i.e., strongly agree, agree, neutral, disagree, strongly disagree). This part of the questionnaire asked the students if the videos helped them in 1) learning about the anatomy of the limbs, 2) their preparation for the laboratory practicals, 3 ) revision following the practicals, 4) preparation for the practical test and 5) compensating for limited their exposure to teaching stations in the laboratory practicals.

Statistical data analysis. Patterns on the utilisation of the videos among students who participated in this study, as well as other categorical variables studied, were explored using frequencies and proportions. The association between the 
utilisation of the videos and students' perception in each of the five learning aspects considered in this study was illustrated using clustered bar charts, and then further investigated using chi-square test of independence (Agresti, 2007). Each perception was initially measured in five point Likert scales, i.e., having five groups. Since some of these groups in our data were considered too small, the "strongly agree" and "agree" groups, as well as the "strongly disagree" and "disagree" groups, were combined in the analyses presented in this paper, resulting in only three groups (strongly agree/agree, neutral and strongly disagree/disagree) for each perception. Gender distribution was explored, and its associations with the utilisation of the videos and perception in each of the five learning aspects were examined using the chi-square test. All data analyses presented in this paper were performed in SPSS version 23.

Ethics. This study was approved by the Macquarie University Human Ethics Research Committee.

\section{RESULTS}

Out of 312 students enrolled in the course, 210 completed the survey (67.3\% response rate). Of them, about $49 \%$ were female and $49 \%$ male, while about $2.9 \%$ stated their gender as "other" or not given. This gender distribution among 210 respondents is consistent with that for the overall 312 students. Although age of respondents ranged from 18 to 39 , the large majority of students (around $88 \%$ ) were in 18 to 22 years of age range, while only about $3 \%$ of students were 30 years of age or older. A total of 181 respondents $(86.2 \%)$ watched the videos. The majority of the students who did not watch the videos $(48.4 \%)$ stated that the reason for this was either the availability of other resources or that they were unaware of the videos available on iLearn (38 $\%$, while only a small proportion stated that they did not believe the videos would be helpful in learning anatomy. The other reasons stated for not watching videos included non-alignment with student's learning style, access problems and, somewhat surprisingly bearing in mind the short length of the videos, time constraints.

There was a total of 8,150 video views. Thus, on average, there were 339.5 views per video. When students were asked how many times they viewed the videos, among the 181 students who watched them, $37.6 \%$ stated more than 10 times, $35.4 \%$ between 5 and 10, and $27.1 \%$ less than 5 times.

Around two thirds of the students who watched the videos perceived them a useful educational tool in learning about the anatomy of the limbs, preparation for the laboratory practicals, revision following the practicals, preparation for the practical test and in compensating for time limited exposure to teaching stations in the laboratory practicals (Table I).

Around one third of them were neutral about the usefulness of the videos. A relatively small proportion (4.4 $\%$ to $15 \%$ ) of students did not find the videos useful, with the highest dissatisfaction recorded in response to if the videos compensated for the time spent in the laboratory. However, this was to be expected given the limited content (muscles only) delivered in the videos.

From Figure 1, it is clear that the more times students watched the videos, the more likely they felt the helpfulness of these videos as a learning tool and teaching resources in various learning aspects studied. Such associations are confirmed by the results from chi-squared tests (p-values < 0.05) shown in Table II.

Furthermore, there were no significant gender differences in the utilization of videos, nor any in the

Table I. Students' perception on the usefulness of videos as teaching resources $(n=181)$.

\begin{tabular}{|c|c|c|c|}
\hline S TATEMENT & $\begin{array}{l}\text { Strongly agree } \\
\text { or agree }(\%)\end{array}$ & Neutral (\%) & $\begin{array}{l}\text { Strongly disagree } \\
\text { or disagre e }(\%)\end{array}$ \\
\hline $\begin{array}{l}\text { The videos helped me learning about the anatomy of the limbs. } \\
\text { [Helpfulness] }\end{array}$ & 68.0 & 27.6 & 4.4 \\
\hline $\begin{array}{l}\text { The videos aided my preparation prior to laboratory practicals. } \\
\text { [AidPracPrep] }\end{array}$ & 56.9 & 32.0 & 11.0 \\
\hline $\begin{array}{l}\text { The videos aided my revision following laboratory practicals. } \\
\text { [AidRevision] }\end{array}$ & 65.6 & 27.2 & 7.3 \\
\hline $\begin{array}{l}\text { The videos helped me in preparation for the practical test. } \\
\text { [AidPracTest] }\end{array}$ & 66.3 & 24.9 & 8.8 \\
\hline $\begin{array}{l}\text { The videos compensate for time limited exposure to teaching } \\
\text { stations in the laboratory practicals. [TimeForLab] }\end{array}$ & 56.4 & 28.2 & 15.5 \\
\hline
\end{tabular}


Table II. Effect of video utilization level on various learning aspects studied $(n=181)$.

\begin{tabular}{llccc}
\hline Learning aspect & \multicolumn{2}{l}{$\begin{array}{l}\text { Percentage of strongly agree/agree (frequency) } \\
\text { by number of times videos were watched: }\end{array}$} & $\begin{array}{l}\text { p-value (based on } \\
\text { chi-square test) }\end{array}$ \\
\cline { 2 - 4 } & $>10$ & $5-10$ & $<5$ & \\
\hline Helpfulness & $56 / 68$ & $47 / 64$ & $20 / 49$ & $<0.0005$ \\
AidPracPrep & $48 / 68$ & $38 / 64$ & $17 / 49$ & 0.001 \\
AidRevision & $53 / 67^{*}$ & $42 / 64$ & $23 / 49$ & 0.005 \\
AidPracTest & $51 / 68$ & $45 / 64$ & $24 / 49$ & 0.009 \\
TimeForLab & $46 / 68$ & $39 / 64$ & $18 / 49$ & 0.013 \\
\hline
\end{tabular}

*: indicating that there is a missing value in AidRevision.

perception of their educational value (p-values > 0.05), among the 181 students who watched the videos.

In the analysis of the students' comments two major themes where captured. Most of the students expressed satisfaction with the length and format of the videos. Commenting on the possible changes, a large number of respondents suggested an increase in the number of videos to include structures other than muscles and captions to assist the visual learners.

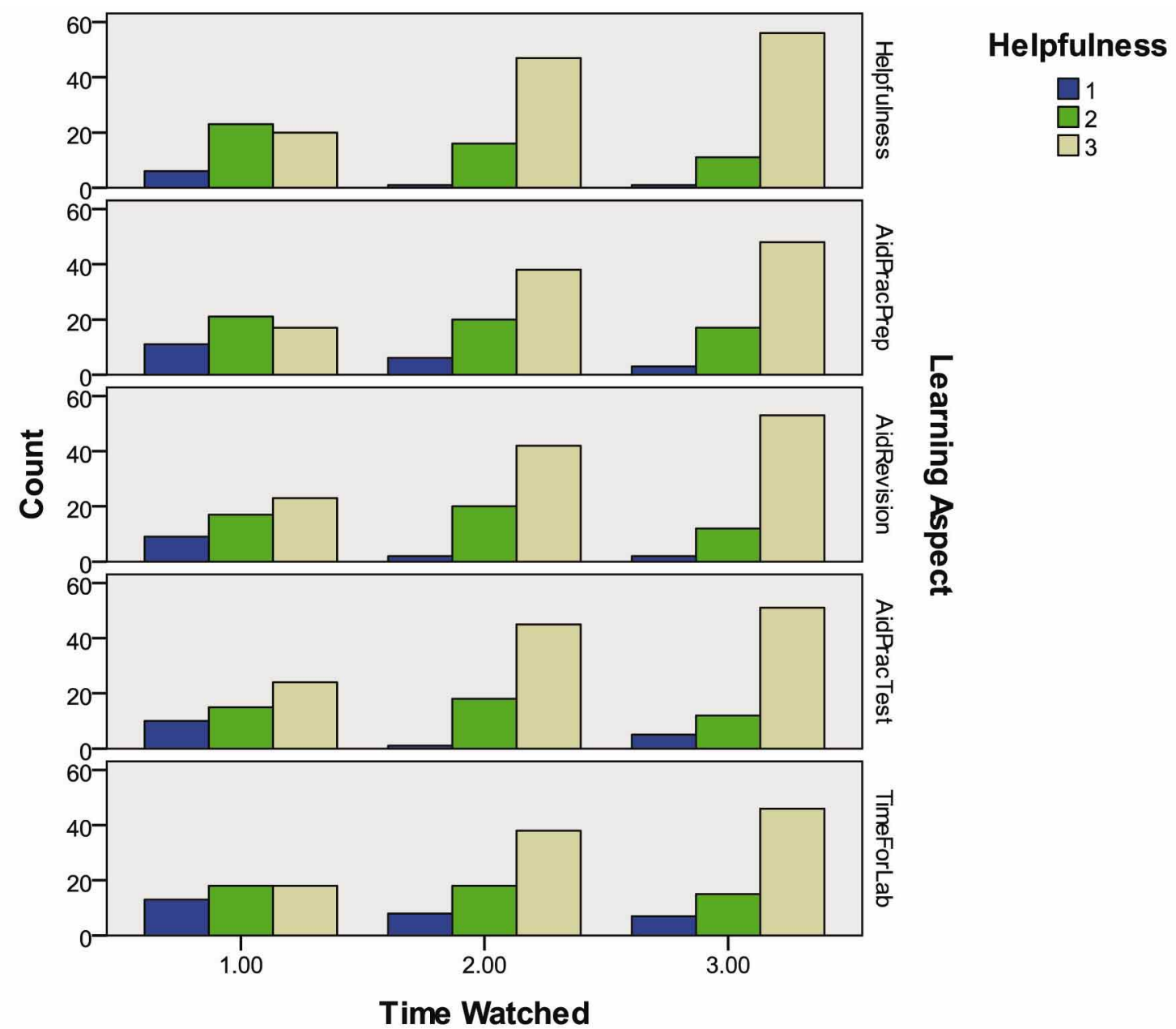

Fig. 1. Students' perception (1/blue for strongly disagree/disagree, 2/green for neutral and 3/beige for strongly agree/ agree) in various learning aspects by utilisation of the videos ( 1 for watching less than 5 times, 2 for 5 to 10 times and 3 for watching more than 10 times). 


\section{DISCUSSION}

Modern technologies offer numerous possibilities for developing efficient educational resources in anatomy. This seems to be of particular importance within the constantly changing landscape of medical education in which contact hours devoted to anatomy seem to be in a steady decline (Drake et al., 2009; Louw et al., 2009; Sugand et al., 2010; Yammine, 2014; Guimarães et al., 2017). Digital media, with which modern students are so familiar and within which they "feel at home", seem to provide opportunities to fill in the possible "gaps" in delivery. They have potential to provide students with additional time to study anatomical structures, at any time and at a pace suited for the individual learner. Videos in particular, if presented in formats appealing to students, could be of educational value and this study seems to suggest this.

The majority of students enrolled in the musculoskeletal anatomy course at Macquarie watched the videos and around two thirds of them reported to perceive them as a useful educational resource as well as a valuable device in revision and preparation for the test. This was despite several other learning tools, delivered in variety of formats, being available to students through Macquarie University and from the public domain. Several other studies also highlighted the potential of videos to be used in preparation for the laboratory and for the revision (Sarikcioglu et al., 2011; Collins et al.). Furthermore, as a locally produced resource the videos had one important advantage - they were tied to the course learning outcomes. Indeed, one of the major problems students experience when utilising external resources, seem to be the non-alignment of these sources with the local learning outcomes (Chu et al., 2013; Hulme \& Strkalj).

Regarding anatomy videos, another problem with both commercial and materials from the public domain, seems to be the fact that they are often compounded by their length and complexity. Students who already feel time pressured are not incentivised to watch lengthy videos and wade through the volume of information which may not be applicable to their course of study. The considerable number of watches of the videos noted in this study, indicates that the length and content specific nature of the videos allows a student to re-watch the particular topic areas where they feel their knowledge is lacking. By categorising the videos into narrow topics, the student can easily find the area they need to study. For a generation of students who are accustomed to high speed and predictive searches for information, being able to easily identify which video they need to re-watch is desirable. Indeed, majority of students who accessed the videos $(74 \%)$, watch them more than five times.
More than half of the students who watched the videos thought that the videos have potential to compensate for limited time in the anatomy laboratory. However, at the same time considerable number of students (around $15 \%$ ) did not see videos as a resource that would accommodate for the limited time spent in anatomy laboratory. One of the main reason for this should probably be sought in the fact that the videos were rather limited in their scope. One might also hypothesise that this is also partly because students did not perceive videos as substitutes for the practical sessions in the lab, but an additional resource that supplement this work.

The minority of surveyed students in this study (less than $14 \%$ ) who did not watch the videos were perhaps the section of the student body who were not very engaged. They were either not motivated to try new resources or, more worryingly, were not aware of their existence (e.g., not familiar with iLearn, or were not utilising it with required regularity). On the other hand, students who did frequently watch the videos tended to find them more useful than those who watched them fewer times. One might assume that when a larger number of videos is offered, covering a greater number of structures, this belief will be even stronger.

The key novelty in application of videos presented in this study was therefore the decision to make them very short, void of redundancy and thus easy to use. Indeed, the videos presented only the essential information. In a way, they were analogous to the tables presenting the summary of skeletal muscles in most of the anatomical textbook. Instead of long narratives on anatomy of the muscles these tables typically have the following columns: muscle, origin, insertion, innervation and function. The tables are thus ideal for quick revision. It was hypothesised that such presentation in a video format would be valued by the Millennial generation of learners, the Digital Natives (Prensky, 2001a,b; Tapscott; Sebri et al., 2016), who were the overwhelming majority of students taking the LB course. The videos were thus adjusted to the twitch speed, appreciated by "the generation who grew up on video games ..., MTV (more than 100 images a minute), and the ultra-fast speed of action films" (Prensky, 1998). The students' positive comments on the format seem to corroborate the hypothesis of the value of short format video clips.

Some authors strongly argue that the generation of Digital Natives have dramatically different learning styles compared to previous generations. They claim that tertiary educators, who are the Digital Immigrants (the older generation who is trying to, or not even attempting to, catch up with the new world of constantly changing digital technologies, or do not recognise the significance of the changes they are witnessing) need to adjust to these emerging 
learning styles. Prensky (2001a) succinctly describes his personal experience of the two approaches (Digital Native vs. Digital Immigrant) while attempting to bridge the intergenerational gap in production of education videos: "The professors had made five-to-ten-minute movies to illustrate the key concepts; we asked them to cut them to under 30 seconds." Indeed, short format presenting information in quanta, is highly utilised in modern communication and some of the social media even have (rather low) limits on the amount of data that can be communicated. While the Digital Native/Immigrants divide might have been overstated (Bennett et al., 2008; Kirschner \& De Bruyckere, 2017), adjusting to new generations of learners whose cognitive apparatus is influenced by digital technology, internet and social media, remains one of the main challenges for contemporary educators (Boulos et al., 2006; Barry et al.).

It would appear that resources based in modern technology, if properly conceptualised and executed, could cater for the demands of new generations of learners whose cognitive constitution seem to be largely shaped by digital technologies. Although videos have a long history of usage in education, digital technologies enabled their easy and efficient production and increased band-width internet speeds allowed immediate availability in accessible and interactive formats.

Limitations. In 2015 academic year LB course at Macquarie University endured some curricular changes. In addition, the student cohort also changed as the course accommodated students from a few newly introduced programs and endured significant increase in student numbers. These changes prevented comparison of the LB course practical exam results of the 2015 with the results of the previous generations of students taking the same course.
Future Developments. Responding to students' feedback, new videos were produced, to cover structures other than muscles. In addition, the original videos were replaced with the newly created ones executed with the assistance of the University's Learning and Teaching Unit and Learning Designers input and training. They were recorded with a $\mathrm{Ca}-$ non XA20 camera, using professional lighting and high quality lapel microphone. Once taped and selected for publication, videos were edited through the Adobe Premiere and Adobe After Effects software to a polished high definition standard. The quality of the video and audio was significantly improved. While the format of the videos essentially stayed the same (some of the new videos were made slightly longer, but none of them lasts more than 2 minutes and 30 seconds), they were further technically improved as they all started with a title (region/structures presented) and had added short text of the names of the structure highlighted in the video to correspond with the voice description, with the intent of increasing the utility from simple labelling through to spelling and pronunciation of complex terms (Fig. 2). In the future more comprehensive studies will focus on the "new generation" of short videos, their utilisation, student satisfaction and their usefulness in achieving the prescribed learning outcomes.

In conclusion, it should be stressed that the shortness of the videos presented in this study made them easy to access and use repeatedly. The videos were utilised with a considerable frequency by a significant number of students who largely find them useful in learning anatomy. In response to students' feedback a new set of videos focusing on structures not accounted for in the existing videos are currently being created. This preliminary study provided a foundation for more indepth research projects, based on the utilisation of the existing and newly produced videos, which might throw more light on the full educational potential of short anatomy video clips.

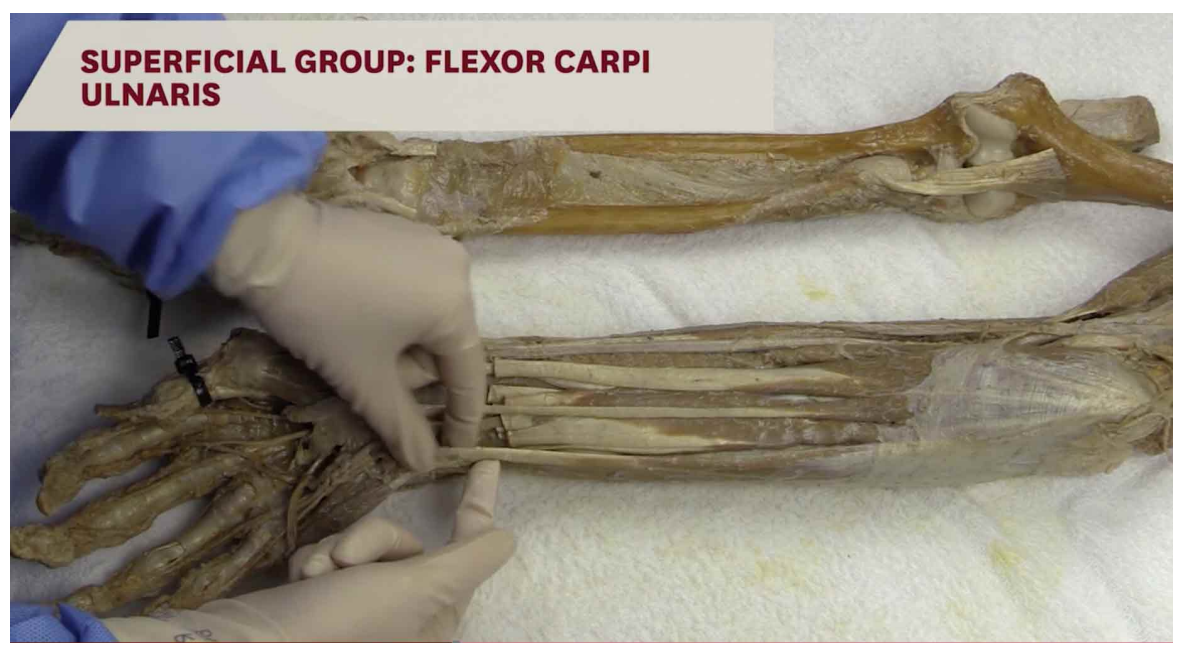

Fig. 2. A screenshot of one of the "second generation" videos.
STRKALJ, G.; HULME, A.; ELHADDAD, J.; LUO, K.; CRAFFORD, D. \& RAMPE, M. Percepciones de los estudiantes y el uso de videos cortos de anatomía: Un estudio preliminar. Int. J. Morphol., 36(2):493-499, 2018.

RESUMEN: Actualmente, aún se está debatiendo la eficacia de los videos en la educación de la anatomía. Posiblemente, uno de los principales factores que desalientan a los estudiantes a usar videos ha sido el tiempo de duración. Para contrarrestar esto, se crearon 24 videos cortos (el más duradero de 1 minuto y 13 segundos) para un curso sobre anatomía musculoesquelética. Los videos se enfo- 
caron en la identificación de los músculos de los miembros y sus relaciones por área. El objetivo de este estudio preliminar fue evaluar la percepción de los estudiantes sobre el valor de los videos y su utilización. Se registró el número de visitas para cada video. Se llevó a cabo una encuesta basada en cuestionarios que se centraron en la percepción de los estudiantes de la utilidad educativa de los videos. En promedio, cada video tuvo 339,5 visitas. De los 312 estudiantes matriculados en el curso, 210 completaron la encuesta (67,3\% de índice de respuesta). Un total de 181 encuestados (86,2 $\%$ ) vieron los videos y la mayoría los percibieron útiles en: Aprender sobre la anatomía de los miembros $(68 \%)$, preparación para el laboratorio $(56,9 \%)$, revisión posterior al laboratorio $(65,7 \%)$ y preparación para la prueba práctica $(66,3 \%)$. Cuando se les pidió retroalimentación, los estudiantes solicitaron un aumento en la cantidad de videos para incluir estructuras distintas de los músculos. Los estudiantes informaron que perciben a los videos como un recurso útil en el curso de anatomía musculoesquelética. La brevedad de los videos los hizo de fácil acceso y posibles de utilizar repetidamente. Estudios más amplios a futuro, basados en la utilización de los videos existentes, como también aquellos producidos recientemente, podrían arrojar más luz sobre su total potencial educativo.

PALABRAS CLAVE: Educación en ciencias anatómicas; Anatomía musculoesquelética; Videos; Anatomía humana.

\section{REFERENCES}

Agresti, A. An Introduction to Categorical Data Analysis. Hoboken, Wiley, 2007.

Bacro, T.; Gilbertson, B. \& Coultas, J. Web-delivery of anatomy video clips using a CD-ROM. Anat. Rec., 261(2):78-82, 2009.

Barry, D. S.; Marzouk, F.; Chulak-Oglu, K.; Bennett, D.; Tierney, P. \& O'Keeffe, G. W. Anatomy education for the YouTube generation. Anat. Sci. Educ., 9(1):90-6, 2016.

Bennett, S.; Maton, K. \& Kervin, L. The 'digital natives' debate: A critical review of the evidence. Brit. J. Educ. Technol., 39(5):775-86, 2008.

Boulos, M. N.; Maramba, I. \& Wheeler, S. Wikis, blogs and podcasts: a new generation of Web-based tools for virtual collaborative clinical practice and education. B. M. C. Med. Educ., 6:41, 2006.

Choi-Lundberg, D. L.; Cuellar, W. A. \& Williams, A. M. Online dissection audio-visual resources for human anatomy: Undergraduate medical students' usage and learning outcomes. Anat. Sci. Educ., 9(6):545-54, 2016.

Collins, A. M.; Quinlan, C. S.; Dolan, R. T.; O'Neill, S. P.; Tierney, P.; Cronin, K. J. \& Ridgway, P. F. Audiovisual preconditioning enhances the efficacy of an anatomical dissection course: A randomised study. $J$. Plast. Reconstr. Aesthet. Surg., 68(7):1010-5, 2015.

Drake, R. L.; McBride, J. M.; Lachman, N. \& Pawlina, W. Medical education in the anatomical sciences: the winds of change continue to blow. Anat. Sci. Educ., 2(6):253-9, 2009.

Granger, N. A. \& Calleson, D. The impact of alternating dissection on student performance in a medical anatomy course: are dissection videos an effective substitute for actual dissection? Clin. Anat., 20(3):31521,2007

Guimarães, B.; Dourado, L.; Tsisar, S.; Diniz, J. M.; Madeira, M. D. \& Ferreira, M. A. Rethinking anatomy: How to overcome challenges of medical education's evolution. Acta Med. Port., 30(2):134-40, 2017.
Hulme, A. \& Strkalj, G. Videos in anatomy education: History, present usage and future prospects. Int. J. Morphol., 35(4):1540-6, 2017.

Jaffar, A. A. YouTube: An emerging tool in anatomy education. Anat. Sci. Educ., 5(3):158-64, 2012.

Kirschner, P. A. \& De Bruyckere, P. The myths of the digital native and the multitasker. Teach. Teach. Educ., 67:135-42, 2017.

Lochner. L.; Wieser, H.; Waldboth, S. \& Mischo-Kelling, M. Combining traditional anatomy lectures with e-learning activities: how do students perceive their learning experience? Int. J. Med. Educ., 7:69-74, 2016.

Louw, G.; Eizenberg, N. \& Carmichael, S. W. The place of anatomy in medical education: AMEE Guide no 41. Med. Teach., 31(5):373-86, 2009.

Mahmud, W.; Hyder, O.; Butt, J. \& Aftab, A. Dissection videos do not improve anatomy examination scores. Anat. Sci. Educ., 4(1):16-21, 2011.

McNulty, J. A.; Sonntag, B. \& Sinacore, J. M. Evaluation of computeraided instruction in a gross anatomy course: a six-year study. Anat. Sci. Educ., 2(1):2-8, 2009.

O'Brien, D.; Caldwell, J.; Culav, E. \& Clark, H. Perceived value of online video demonstrations as an adjunct to learning surface anatomy for physiotherapy students. Focus Health Prof. Educ., 16(4):83-5, 2015.

Ogunranti, J. O. Video technology in integrated anatomy education. Educ. Ind. Telev., 13(1):63-7, 1987.

Prensky, M. Digital Natives, Digital Immigrants Part 1. On the Horizon, 9(5):1-6, 2001a.

Prensky, M. Digital Natives, Digital Immigrants Part 2: Do they really think differently? On the Horizon, 9(6):1-6, $2001 \mathrm{~b}$.

Prensky, M. Twitch Speed. Keeping Up with Young Workers, 1998. Available from: http://www.marcprensky.com/writing/Prensky\%20\%20Twitch\%20Speed.html

Sarikcioglu, L.; Senol, Y.; Yildirim, F. B. \& Hizay, A. Correlation of the summary method with learning styles. Adv. Physiol. Educ., 35(3):2904, 2011.

Saxena, V.; Natarajan, P.; O'Sullivan, P. S. \& Jain, S. Effect of the use of instructional anatomy videos on student performance. Anat. Sci. Educ., 1(4):159-65, 2008.

Sebri, I.; Bartier, J. C. \& Pelaccia, T. How do nursing students use digital tools during lectures? PLoS One, 11(11):e0165714, 2016.

Sugand, K.; Abrahams, P. \& Khurana, A. The anatomy of anatomy: a review for its modernization. Anat. Sci. Educ., 3(2):83-93, 2010.

Tapscott, D. Growing up Digital: How the Net Generation is Changing your World. New York, McGraw Hill, 2008.

Topping, D. B. Gross anatomy videos: student satisfaction, usage, and effect on student performance in a condensed curriculum. Anat. Sci. Educ., 7(4):273-9, 2014.

Trelease, R. B. From chalkboard, slides, and paper to e-learning: How computing technologies have transformed anatomical sciences education. Anat. Sci. Educ., 9(6):583-602, 2016.

Yammine, K. Evidence-based anatomy. Clin. Anat., 27(6):847-52, 2014.

\section{Corresponding author: \\ Goran Strkalj}

Department of Chiropractic

Faculty of Science and Engineering

Macquarie University

Sydney

AUSTRALIA

Email: goran.strkalj@mq.edu.au

Received: 21-11-2017

Accepted: 27-01-2018 